\title{
CONFLUÊNCIAS ENTRE ARTE E TECNOLOGIA EM “MARCELO DO CAMPO 1969 - 1975”
}

CONFLUENCES BETWEEN ART AND TECHNOLOGY IN "MARCELO

DO CAMPO 1969 - 1975"

Lívia Nagao

UEPG-PR

Laura Castr Cristina Mendes

UEPG-PR

\begin{abstract}
Resumo: $O$ artigo tem por objetivo tecer reflexões sobre Marcelo do Campo (1951), artista criado por Dora Longo Bahia em sua dissertação de mestrado em Poéticas Visuais (ECA/USP, 2003). Busca-se também analisar a presença da tecnologia na obra de Do Campo, correla-cionando-a ao período da Ditadura Militar no Brasil. A pesquisa se justifica devido aos limites entre a realidade e a simulação na pesquisa de Bahia. A metodologia consiste na análise da dissertação, com base em Marcel Duchamp e pseudônimos, Fernando Pessoa e heterônimos e Jean Baudrillard e simulacros na contemporaneidade.
\end{abstract}

Palavras-Chave: Marcelo do Campo, Arte e Tecnologia, Simulacro.

Abstract: The objective of this article is to reflect on Marcelo do Campo (1951), an artist created by Dora Longo Bahia in her master's dissertation in Visual Poetics (ECA/USP, 2003). It also aims to analyze the presence of technology in Do Campo's work, correlating it to the Mili-tary Dictatorship period in Brazil. The research is justified by the limits between reality and simulation Bahia's research. The methodology consists on the analysis of the disserta-tion, based on Marcel Duchamp and pseudonyms, Fernando Pessoa and heteronyms and Jean Baudrillard and simulacra in the contemporaneity.

Keywords: Marcelo do Campo, Art and Technology, Simulacrum. 


\section{Introdução}

Marcelo do Campo, artista visual fictício criado por Dora Longo Bahia em sua dissertação de mestrado, nasce em São Paulo, em 1951, e tece críticas políticas e sociais em suas obras. Sua produção artística acontece entre os anos 1969 e 1975, denunciando a tortura e a censura que permeiam a cultura brasileira do período. São algumas das obras de Do Campo: A bout de souffle (1969), Quand les attitudes déforment les altitudes (1969), Ambiência 2 (1971) e Le déjeuner sur l'herbe (1974).

O objetivo deste trabalho é estabelecer reflexões sobre as obras supracitadas, enfatizando as escolhas tecnológicas adotadas por Bahia e enfatizando a relação entre a poética da artista e a relação com a Ditadura Militar. Tal investigação se justifica pelo fato de que os limites entre realidade e simulação se ampliam significativamente na pesquisa de Bahia, o que nos leva à indagação acerca das estratégias através das quais o processo de criação, levado a cabo por ela, complexifica e subverte os estudos sobre Arte brasileira.

Dentre as obras ficticiamente produzidas por Do Campo, destacamos a produção de vídeos, por exemplificarem o difícil acesso aos equipamentos tecnológicos no período, supostos dificultadores da produção em questão. 0 registro de imagens fílmicas das décadas de 1960 e 70 foi amplamente destruído no Brasil, pois questões políticas poderiam incriminar seus criadores. Tal fato potencializa a discussão sobre o destino de obras e artistas que, como Marcelo do Campo, atuaram neste período.

O legado de Marcel Duchamp e sua relevância para a história da arte é destacado por Bahia já na identificação do artista. A criação de um personagem fictício pode também ser relacionado a Fernando Pessoa, que em sua estreita relação os heterônimos, consegue atribuir a cada um deles personalidades distintas. Finalmente, encontramos na teoria do simulacro de Jean Baudrillard, subsídios para a compreensão do processo criativo de Dora Longo Bahia e da presença de elementos que subvertem o conceito de real na contemporaneidade.

\section{Marcelo do Campo - Ficção e Realidade}

Dora Longo Bahia utiliza-se da ideia de persona, assumindo o papel de um personagem em dado contexto social e histórico, desprendendo-se de sua própria personalidade. Neste caso, adota a identidade do artista contemporâneo Marcelo do Campo, problematizando ficção e realidade ao criar biografia e obras de arte (NUNES, 2013; FERREIRA, 2017).

Ao se desvincular de sua própria personalidade, a artista inspira-se em Fernando Pessoa, criando um heterônimo do sexo masculino, que vive em uma época distinta e que nada tem em comum com ela, histórica ou artisticamente. A autora cria uma linha do tempo detalhada sobre acontecimentos da vida de Marcelo do Campo, a qual tem um importante papel na produção das obras.

De acordo com Yiftah Peled (2012), Bahia constrói uma ficção que desperta desconfiança por parte do leitor. A artista provoca incertezas com relação às datas de nascimento e desaparecimento de Marcelo do Campo, bem como da veridicidade de sua existência e de suas obras. 0 artista pesquisador pontua ainda que:

Para Longo Bahia, toda obra de arteé um estado de suspensão entre a realidade e sua representação. Assim, ela explora no seu texto uma relação sobre a natureza da obra de arte em artistas como Smithson e Duchamp, bem como o uso de heterônimos por artistas como Duchamp e Fernando Pessoa (PELED, 2012, p. 128).

Tais apropriações ocorrem devido à própria narrativa da autora, que conta como encontra 
as obras de Do Campo na Biblioteca da FAU -USP, sendo todas efêmeras, registradas em forma de fotos e vídeos de pouca qualidade. Ela aproveita as condições da época em que Do Campo atua, para simular as obras, causando a sensação de que foram feitas naquele período.

Fotos, vídeos e a própria existência de Do Campo, são espécies de simulacros, pois representam uma realidade que nunca existiu, e que, através de processos de criação da artista, se incorporam ao mundo das coisas, complexificando os limites do real. Nely Klix Freitas (2013) aponta que as imagens simulam algo ao qual não temos acesso, fazendo com que possamos acreditar que aquilo que vemos realmente existe. A criação de simulacros, para Baudrillard (1991), se relaciona à produção de sentidos, na qual o distanciamento é um fator relevante, pois colabora para a perda da clareza daquilo que pode ter sido o real.

Em estratégias que têm por meta dar maior visibilidade a Marcelo do Campo, dados sobre sua vida e obra podem ser encontrados, além da dissertação de Bahia, em páginas eletrônicas como a Enciclopédia Itaú Cultural, o Museu de Arte Moderna de São Paulo, bem como na página oficial do artista. Tais plataformas potencializam a discussão entre ficção e realidade estabelecidas pela artista.

Bahia utiliza-se das novas mídias para a criação de Marcelo do Campo, uma vez que as evidências da existência do artista, na Internet, se misturam à presença de artistas reais midiatizados pelos meios de comunicação de massas. Sobre a relação da arte com as mídias, Arlindo Machado (2010, p.10) pontua que "as artes midiáticas representam a expressão mais avançada da criação artística atual e aquela que melhor exprime sensibilidades e saberes do homem do início do terceiro milênio".

Dados da dissertação de Bahia e do site oficial de Do Campo, relatam que o artista muda-se para Florianópolis em 1975 e não se sabe mais seu paradeiro desde então. Porém, em Peled (2012), encontramos informações de que Marcelo do Campo fora encontrado em Santa Catarina, sob o nome de Marcelinho Campeche, e que continua produzindo obras de arte em conjunto com outros artistas da região. Além disso, na Internet nos deparamos com um site no qual é possível ver fotos e áudios da exposição da qual ele participa, no ano de 2011, em Florianópolis.

\section{Vídeo-arte e Simulação}

As obras em vídeo de Marcelo do Campo, segundo as informações oficiais, foram produzidas em Super-8, entre os anos 1969 e 1974. De acordo com a ficha técnica de Bahia (2003), algumas das obras (A bout de soufflé e Quand les attitudes déforment les altitudes) foram feitas na tecnologia desenvolvida nos anos 60, enquanto as outras (Ambiência 2 e Le déjeuner sur l'herbe) foram produzidas através de vídeo digital, simulando a realidade daquela época. Isto nos leva a concordar com Freitas (2013), quando afirma que as imagens não são cópias fiéis da realidade e sim artifício para simular algo a que não se tem acesso direto. As imagens passam a constituir o mundo, o qual não mais existe, senão associado a elas. Portanto, independentemente do método com o qual os vídeos foram feitos, seu resultado evidencia a manipulação da realidade, com o intuito de fazer crer que os trabalhos foram executados por Marcelo do Campo, artista que teve uma vida concreta e real.

O primeiro trabalho que analisaremos é $A$ bout de soufflé, de 1969, filmado em Super-8 em Sierre, na Suiça, em 2001. Do Campo se apropria do título de um filme homônimo de Jean-Luc Godard, o qual, lançado em 1961, aborda questões contraculturais que marcaram a época. 0 longa-metragem Acossado, na tradução para o português, trata do romance entre um ladrão de 
Figura 1. A bout de soufflé - Marcelo do Campo, 1969 (Fonte: marcelodocampo.org

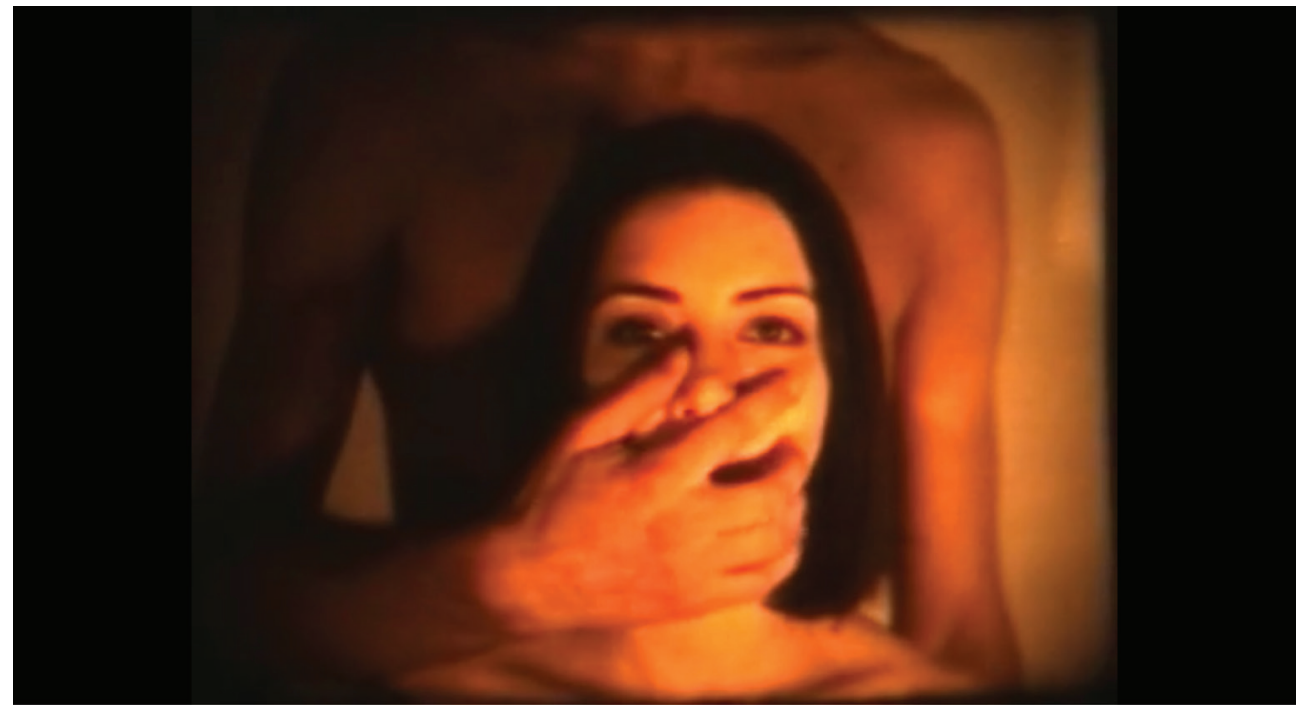

carros e uma jovem norte-americana, exploranUma das questões pungentes na dissertação do as tentativas de fuga e a complexidade das relações afetivas. No vídeo, de aproximadamente três minutos, vemos a imagem de uma jovem sendo lentamente asfixiada por um rapaz. A moça consegue desvencilhar-se algumas vezes das mãos dele, mas volta a ter a boca e o nariz fechados até o final da projeção. de Bahia é a abordagem de questões relativas ao feminino (2003, p. 64). Neste vídeo, podemos estabelecer relações com abuso, violência doméstica e submissão, fatores a que muitas muIheres estão sujeitas. Além disso, a posição da personagem, sentada abaixo ao seu agressor, numa tomada em plongée, pode ser uma alusão

Figura 2. Quand les atitudes déforment les altitudes - Marcelo do Campo, 1969 (Fonte: marcelodocampo. org).

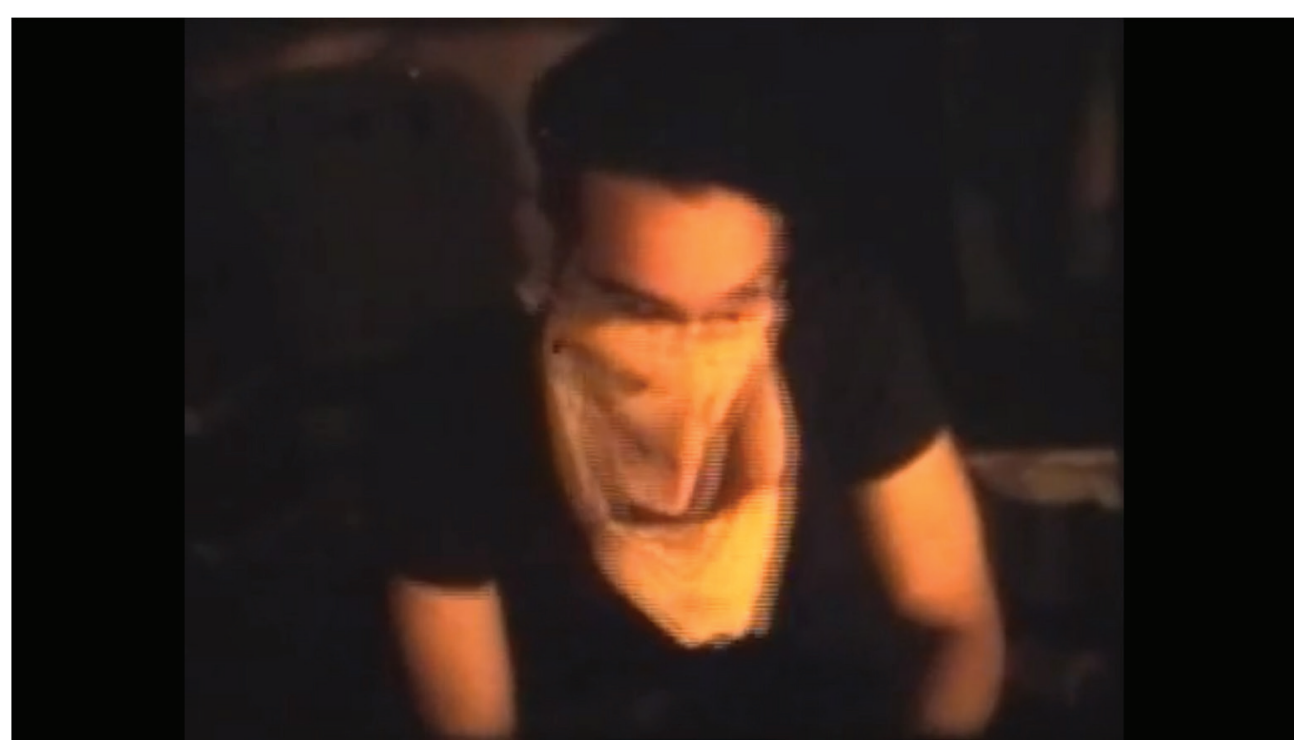


à suposta inferioridade das mulheres e ao modo como eram tratadas na década de 60 , problema que se estende à atualidade. 0 fato de o vídeo não possuir som, potencializa ainda mais o silêncio da vítima, evidenciando a falta de voz que pressupõe a necessária obediência da mulher na época.

O segundo vídeo a ser analisado, Quand les atitudes déforment les altitudes (1969), foi filmado no mesmo formato e local do anterior. Faz parte de uma ação coletiva realizada pelo grupo FOEHN, do qual Do Campo participa, e tem duração de aproximadamente onze minutos. 0 vídeo mostra momentos do grupo, enquanto vivem dentro de um bunker de papelão em Berna, também na Suiça.

A partir do título da obra, podemos estabelecer uma relação com a exposição When Attitudes Become Form organizada por Harald Szeeman e realizada em Berna, na Suíça, em 1969. A mostra é considerada um dos eventos mais importantes de Arte Conceitual já realizado na Europa. Contou com diversos artistas experimentais, que trabalharam em projetos nos quais produ- ziam livremente. Assim como Do Campo, estes artistas davam ênfase ao processo de criação e preferiam exibir suas obras em espaços não oficiais, em atitudes que colocavam em xeque a supremacia dos espaços oficiais de exibição artística.

Tanto A bout de soufflé, quanto Quand les attitudes déforment les altitudes foram ficticiamente produzidas por Marcelo do Campo durante seu período de estadia na Suíça. Ou seja, além de utilizar a mesma técnica da época para criar as obras, Bahia ainda tenta aprimorar a simulação destas, criando-as no mesmo local onde teriam sido feitas por Do Campo.

O terceiro trabalho sobre o qual tentamos tecer algumas reflexões é Ambiência 2, realizado em 1971. Este é um vídeo de 27 minutos, sem som, que mostra uma jovem, a própria artista, vestida com roupas militares e olhando fixamente para frente. Ela tem seu rosto estapeado por um homem mascarado que a rodeia durante a filmagem. A personagem, bem maquiada e penteada, nada faz para evitar os maus tratos e a submissão à outra figura. Para Peled (2012),

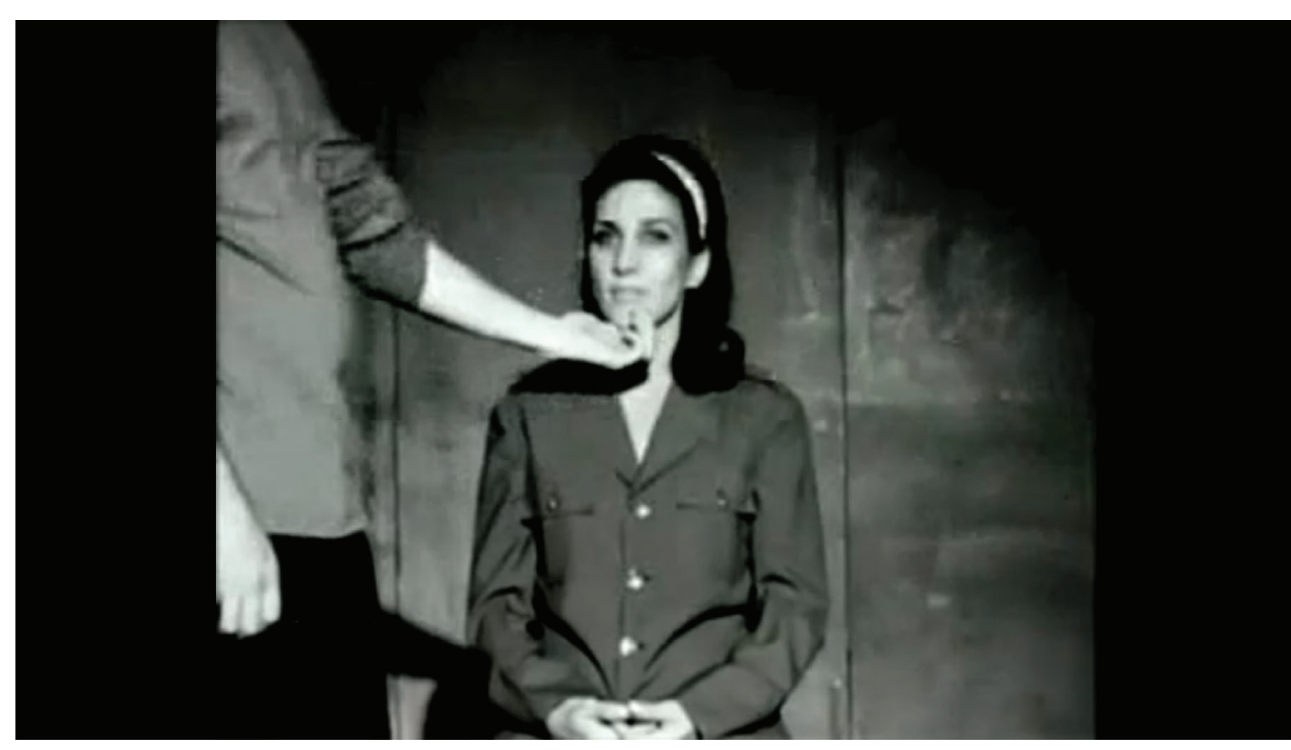


o vídeo em preto e branco com a artista estática permite concluir que o torturador seria o fantasma por ela criado, o qual se tornou mais potente que a própria artista. No final do vídeo, podemos vê-la chorando, numa encenação da exaustão causada pelo sofrimento.

Assim como em A bout de soufflé, nesta obra é novamente possível criar conexões com o feminino. Possivelmente, este seria um dos motivos pelos quais Bahia participa como protagonista da obra, numa evidência de que o lugar da arte produzida por mulheres é até hoje problemático:

Características semelhantes nas obras de artistas do sexo feminino e masculino geram interpretações diferentes; muitos aspectos são considerados parte integrante de um abstrato universo feminino se presentes na obra de artistas mulheres, enquanto, se presentes no trabalho de artistas do sexo masculino, são analisados segundo critérios formais ou estéticos (BAHIA, 2003, p. 64).

Outro aspecto que podemos analisar são as vestimentas militares usadas por Bahia, as quais, de saída representam a inversão de valores vigen- tes no período. O fato de que pessoas que contrariavam o sistema da Ditadura Militar sofriam retaliações, tais como violência e tortura, é potencializado em complexos sistemas interpretativos, dentre os quais destacamos a presença do sofrimento da artista no vídeo, numa alusão à impossibilidade de livre expressão.

O último vídeo por nós destacado, Le déjeuner sur l'herbe, data de 1974, com duração de cerca de doze minutos. Trata-se de uma releitura da obra homônima de Édouard Manet, e mostra o corpo de uma jovem nua, deitada em cima de uma mesa. Uma figura masculina, vestida de terno tenta acordá-la, acariciando, beijando e, por vezes, lambendo a jovem inconsciente. Bahia (2003) esclarece:

A câmera é fragmentada e trêmula, gerando uma sensação nauseante no observador. Marcelo relaciona, aqui, questões artísticas com questões éticas. Relendo a obra homônima de Manet, transforma a jovem nua numa Branca de Neve contemporânea, imersa num sono de morte à espera do príncipe (BAHIA, 2003, p.53).

A pintura Le déjeuner sur l'herbe (1863), de Manet, é considerada um dos pontos de parti-
Figura 4. Le déjeuner surl'herbe - Marcelo do Campo, 1974 (Fonte: marcelodocampo. org).

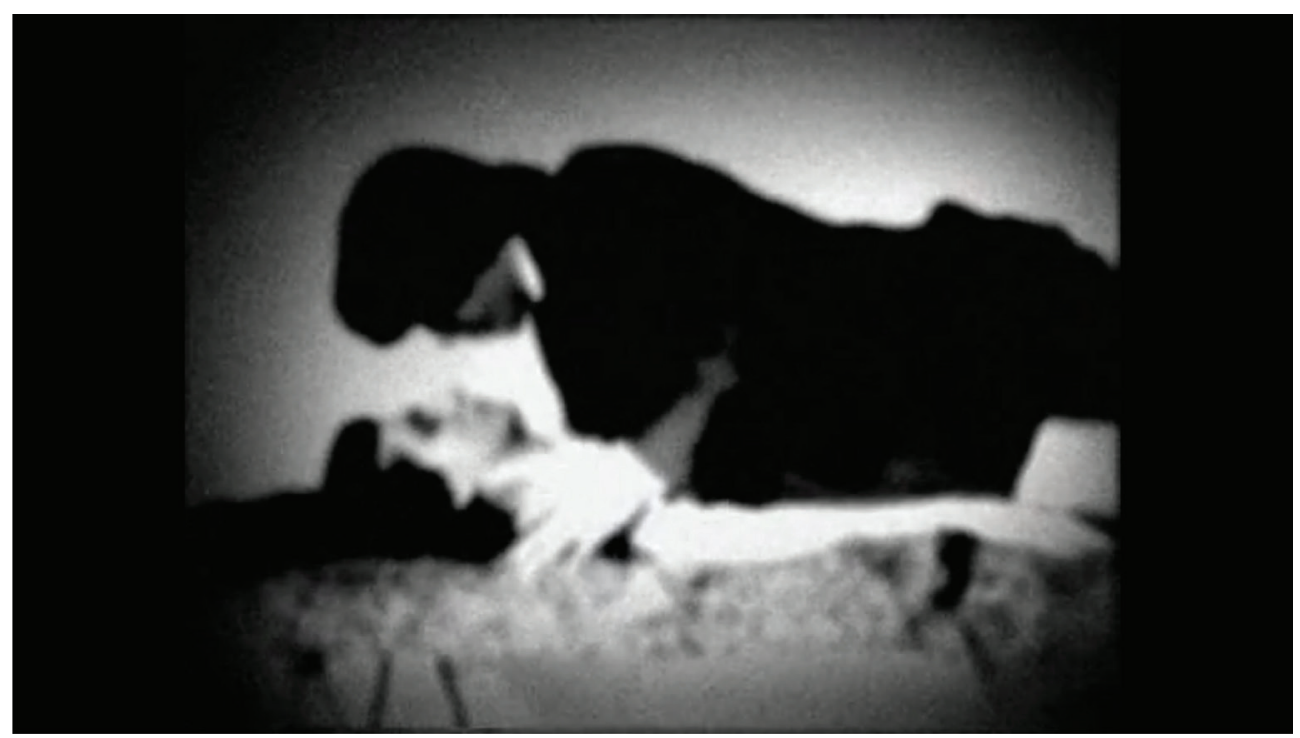


da da Arte Moderna, por abandonar os modelos tradicionais de arte e buscando maior liberdade de expressão. A obra, que foi um choque para a sociedade da época, conta com a presença de uma mulher nua com dois homens vestidos e não possui profundidade e perspectiva, além de adotar o uso de cores exageradamente contrastantes.

Assim como a obra de Manet, o vídeo também é chocante e impactante, pois o personagem masculino aproveita-se da mulher, fazendo com que o espectador possa somente assistir à cena, sem poder fazer nada para ajudá-la a sair de tal situação. Pode-se estabelecer aqui, uma correlação com fatos que aconteceram com grande parte da sociedade brasileira, que nada pôde fazer para amparar aqueles que foram torturados ou mortos durante a Ditadura Militar.

Ambiência 2 e Le déjeuner sur l'herbe foram produzidas a partir de vídeo digital no ano 2000. Apesar disso, as duas são simulações de vídeos em super-8, que datam de 1971 e 1974 respectivamente. Além disso, em ambas há participação de Bahia como um dos personagens. Bahia (2003) ainda discute em sua dissertação, o fato de que as obras de Marcelo do Campo são reais, porém, em um falso contexto, uma vez que foram executadas e documentadas por ela mesma.

\section{Conclusões}

A partir da pesquisa foi possível compreender que a relação entre realidade e simulação, mote para artistas modernos e contemporâneos, pode criar um amálgama de referências, cujo alcance se estende para inúmeros campos investigativos. Os processos de criação, portanto, tecem uma espécie de urdidura de sentidos até chegar à concretização da obra, a qual pode ser mais bem apreendida tendo por base tais informações.

As reflexões tecidas sobre a criação de Mar- celo do Campo, trabalho de Dora Longo Bahia, amplificaram o campo da arte, como também tornaram evidentes as estratégias adotadas pela artista para fazer com que as obras produzidas sejam temporalmente contextualizadas e integrem o conjunto de obras brasileiras produzidas no período da Ditadura Militar.

Os vídeos analisados são apenas algumas das obras de Do Campo, mas são suficientes para mostrar a preocupação que os artistas das décadas de 60 e 70 tinham em denunciar e protestar contra um sistema de opressão que os tentava calar. Ao mesmo tempo, representam um alto grau de compexificação do meio artístico, incluindo em seus registros um artista ficcional, cuja vida, com a realização da obra de Peled, transcende o domínio de sua criadora.

Tais processos de apropriação e de simulação parecem convergir para o desmantelamento de conceitos tais como realidade e autoria, fartamente discutidos nas últimas décadas. Destacamos, na obra de Bahia, a dificuldade para estabelecer critérios de discernimento diante de uma abordagem superficial, percebendo que o aprofundamento dos conceitos adotados pela artista permite maior fruição estética e compreensão da obra. A criação de Marcelo do Campo e de seus vídeos atesta a capacidade de amplitude das Artes Visuais, em processos de valorização de nosso legado tecnológico e cultural.

\section{Referências}

BAHIA, D. L. Do Campo a Cidade. 2010. 207p. Tese (Doutorado) - Escola de Comunicações e Artes, Universidade de São Paulo, 2010.

BAHIA, D. L. Marcelo Do Campo 1969 - 1975. 2003. 77p. Dissertação (Mestrado) - Escola de Comunicações e Artes, Universidade de São Paulo, 2003.

BAUDRILLARD, J. Simulacros e Simulações. Lisboa: Relógio d'Água, 1991. 
CONTEMPORARY ART DAILY. "When Attitudes Become Form" atFondazione Prada. Disponível em: < http:// www.contemporaryartdaily.com/2013/09/when-attitudes-become-form-at-fondazione-prada/> Acesso em 07 Out. 2018.

FERREIRA, E. C. A ficção na pesquisa em arte e educação: uma breve aproximação. VIS - Revista do Programa de Pós-Graduação em Arte da UnB. v.16, n.2, p.259-277, 2017.

FREITAS, N. K. Representação, Simulação, Simulacro e Imagem na Sociedade Contemporânea. Polêm!ca, v. 12, n.2, abr/jun, 2013.

MACHADO, A. Arte eMídia. 3a ed. Rio de J5hhbaneiro: Jorge Zahar Ed., 2010.

MAM. Marcelo do Campo. Disponível em:<http:// mam.org.br/artista/campo-marcelo-do/> Acesso em 21 Set. 2018.

MARCELO do Campo. In: ENCICLOPÉDIA Itaú Cultural de Arte e Cultura Brasileiras. São Paulo: Itaú Cultural, 2018. Disponível em: <http://enciclopedia.itaucultural. org.br/pessoa364820/marcelo-do-campo>. Acesso em: 21 Set. 2018.

Marcelo do Campo. Biografia. Disponível em:<https://marcelodocampo.org/> Acesso em 21 Set. 2018. Marcelinho Campeche. Disponível em:< http://www. dobbra.com/contemporao/MC/MarcelinhoCampeche.html>Acesso em:21 Set. 2018.

MUSÉE D'ORSAY. Edouard Manet - Luncheon on the Grass. Disponível em: < http://www.musee-orsay.fr/ en/collections/works-in-focus/search/commentaire/ commentaire_id/luncheon-on-the-grass-7201.html> Acesso em 06 Out. 2018.

NUNES, F. O. Artistas da web e suas personas: algumas reflexões. $4^{\circ}$ Encontro Internacional de Grupos de Pesquisa. Instituto de Artes da UNESP, São Paulo, 2013.

PELED, Y. Metodologias em Poéticas Visuais. Revista Porto Alegre. v.19, n.33, nov/2012. 